\title{
1 On the Freezing Time of Supercooled Drops in Developing
}

\section{Convective Clouds}

3

4 Jing Yang ${ }^{1}$, Zhien Wang ${ }^{1}$, and Andrew Heymsfield ${ }^{2}$

5 [1] \{Department of Atmospheric Science, University of Wyoming, Laramie, WY\}

6 [2] \{National Center for Atmospheric Research, Boulder, CO $\}$

7 Correspondence to: Zhien Wang (zwang@uwyo.edu)

12 Abstract

13 In this study, the particle size distributions (PSDs) measured in fresh developing maritime

14 convective clouds sampled during the Ice in Clouds-Tropical (ICE-T) project are shown and

15 compared with the PSDs modeled using a parcel model containing a spectral bin microphysics

16 scheme. The observations suggest that the "first ice" in convective clouds is small. To interpret

17 the observed ice PSDs, the freezing times and temperatures of supercooled drops are analyzed.

18 The results indicate that the freezing time is longer for large drops than it is for small drops. Due 
to instrumental limitations, freezing drops cannot be identified until they exhibit obvious shape deformation. If the updraft is strong enough, large freezing drops can be carried upwards to a lower temperature than their nucleation temperature before obvious shape deformation occurs. In models, drop freezing is assumed to be instantaneous, which is not realistic; thus, the model yields a broader "first ice" PSD than is observed. This study allows us to interpret the observed ice PSDs in fresh developing convective clouds from the perspective of the freezing time of supercooled drops and notes the deficiency of instantaneous drop freezing in models. To better understand the mechanisms of drop freezing and ice initiation in convective clouds, more laboratory experiments and in situ measurements are needed in the future.

\section{Introduction}

Ice initiation in convective clouds is still not well understood (Cantrell and Heymsfield, 2005;

Lawson et al., 2015; Yang et al., 2016), and it remains one of the main sources of uncertainties in numerical models (Khain et al., 2015). Observations suggest that ice initiation in convective clouds is strongly related to the freezing of supercooled drops (Rangno and Hobbs, 2005; Lawson et al., 2015; Yang et al., 2016; Field et al., 2017). Supercooled drops do not fully freeze instantaneously, and during airborne measurements, freezing drops cannot be observed until they have experienced obvious deformation. The freezing rate of supercooled drops depends on the rate of heat transfer between the drop and ambient air (Pruppacher and Klett, 1997). Typically, the freezing process comprises four stages (Hindmarch et al., 2003): 1) the supercooling stage, during which a drop is supercooled to its nucleation temperature; 2) the recalescence stage, during which rapid kinetic ice nucleation occurs, which results in a rapid drop in temperature that

40 is terminated when the drop temperature reaches $0{ }^{\circ} \mathrm{C} ; 3$ ) the freezing stage, during which the

41 liquid part of a drop continuously freezes and the drop temperature remains at $0{ }^{\circ} \mathrm{C}$; and 4 ) the 
42 cooling stage, during which the frozen drop cools to the ambient temperature.

43 A number of laboratory experiments have been performed to study the freezing of supercooled

44 drops. For example, Johnson and Hallett (1968) showed that the freezing time of supercooled drops decreases with decreasing ambient temperature. In typical air conditions, it takes approximately $400 \mathrm{~s}$ for a stationary millimeter-sized drop to completely freeze at $-5^{\circ} \mathrm{C}$ under a pressure of $1 \mathrm{~atm}$; this freezing time is reduced to approximately $200 \mathrm{~s}$ at $-10{ }^{\circ} \mathrm{C}$. They also showed that the freezing rate of supercooled drops is related to the composition of air and that the freezing time of a millimeter-sized drop in helium and hydrogen is only one-fifth of that in air. Hindmarsh et al. (2003) showed that the freezing time increases with increasing drop size. In addition, Hindmarsh et al. (2003) used experimental results to discuss the accuracy of three drop freezing models: the uniform temperature model, the inward freezing model and the outward freezing model. All three of these models have fairly good accuracy in modeling drop temperatures and freezing times, and there are only minor differences between them.

In most numerical weather prediction models (NWPMs) and global climate models (GCMs), the freezing of supercooled drops is assumed to be instantaneous, because it is difficult to track the freezing stage of every particle in models and because there are no good observations with which to evaluate the modeled ice microphysics in detail. Phillips et al. (2015) implemented timedependent freezing for raindrops in a cloud model using spectral bin microphysics (SBM). Their sensitivity tests showed that time-dependent drop freezing delays the formation of hail in convective clouds; however, their model was unable to track the freezing stage of every particle. Using a simplified cloud parcel model and an electromagnetic scattering model, Kumjian et al.

63 (2012) showed that the modeled radar polarimetric variables for convective clouds are more 64 consistent with observations if time-dependent drop freezing is considered. However, drop 
freezing in fresh developing convective clouds has rarely been discussed. Thus, to better understand ice initiation in convective clouds and to evaluate the modeled microphysics, more observations are needed.

Aircraft in situ measurements are necessary to improve our current understanding of ice initiation in convective clouds and to evaluate model simulations. Traditional in situ measurements can rarely identify ice that is smaller than $200 \mu \mathrm{m}$ in diameter. The 3 -View Cloud Particle Imager (3V-CPI) is a good tool with which to record small particle images, and it can be used to identify small ice (Field et al., 2017). During the Ice in Clouds-Topical (ICE-T) project, the 3V-CPI that was operated on the SPEC Learjet yielded high-resolution particle images and particle size distributions (PSDs). The 3V-CPI measurements suggest that the observed "first ice" in fresh developing convective clouds are all small ice (Lawson et al., 2015); however, the results of some other studies have suggested that larger supercooled drops may freeze before smaller drops (Bigg, 1953; Heymsfield, 2013). This raises the question: why is the observed helpful for interpreting the observed ice PSDs in developing convective clouds. In addition, determining the size of "first ice" is important for understanding secondary ice generation

81 process(es). This study aims to analyze the observed PSDs in developing convective clouds

82 using the data collected during the ICE-T project, as well as to interpret these observations

83 through the perspective of the freezing time of supercooled drops. This paper is organized as

84 follows: Section 2 introduces the dataset and the analytical method; Section 3 discusses the

85 results; and a summary is given in Section 4.

\section{2. Dataset and Analysis Method}




\subsection{Calculation of the freezing time of supercooled drops}

The calculation of the freezing time and temperature of supercooled drops is governed by a series of heat transfer and phase change equations. These detailed equations have been described in previous studies (e.g., Dye and Hobbs et al., 1968; Hindmarsh et al., 2003). The drop temperature change is balanced by convective heat transfer (i.e., ventilation), radiation and latent heat terms. In this calculation, a supercooled drop is assumed to be carried upward by an updraft, which ascends adiabatically. The terminal velocity of the drop follows that defined by Foote and Du Toit (1969). In this calculation, diffusional growth is included but coalescence is neglected. The initial drop temperature is the same as the ambient air temperature. The temperature inside the drop is assumed to be uniform; this is a reasonable assumption because water and ice have a larger thermal conductivity than air and because of the internal mixing of liquid within the drop (Yao and Schrock, 1976). Hindmarsh et al. (2003) showed that including temperature variations inside the drop has a minor impact on the results. The freezing time is defined as the time period from the start to the end of the drop freezing.

\subsection{Aircraft measurements during ICE-T}

The ICE-T project was conducted in July 2011 over the Caribbean Sea, near the U.S. Virgin Islands; its goal was to study ice generation in tropical maritime convective clouds. Both the National Center for Atmospheric Research (NCAR) C-130 aircraft and the SPEC Incorporated Learjet were deployed during ICE-T.

The SPEC Learjet was equipped with various instruments that were used to study the microphysics in convective clouds during ICE-T. The primary goal of the Learjet was to make repeated penetrations in fresh developing convective updrafts near the cloud top. These 
instruments included a fast forward-scattering spectrometer probe (FFSSP); a CPI; a two-

110 dimensional stereo (2D-S) probe; a high-volume precipitation spectrometer (HVPS-3), and a

111 Rosemount temperature probe. The measurements obtained using the FFSSP, CPI, 2D-S, and

112 HVPS were combined to generate the PSDs. CPI images were used to identify liquid drops and

113 ice particles that were smaller than $500 \mu \mathrm{m}$ in diameter, and these percentages of drops and ice

114 particles were applied to the 2D-S PSDs. The 2D-S and HVPS images were used to identify

115 drops and ice particles that were larger than $500 \mu \mathrm{m}$ in diameter. More information about the

116 processing of the Learjet data can be found in Lawson et al. (2015).

117 The NCAR C-130 was not used to repeatedly penetrate fresh developing convective clouds

118 during ICE-T; instead, it penetrated convective clouds at different stages of their development.

119 Most of these penetrations occurred far below the cloud top, although some were near the cloud

120 top (Heymsfield et al. 2014). The instruments used here included an FFSSP, a two-dimensional

121 cloud (2D-C) probe, a two-dimensional precipitation (2D-P) probe, and a Rosemount temperature probe. The Wyoming Cloud Radar (WCR; Wang et al. 2012) was operated on the C130 to obtain 2D reflectivity structures, and the Wyoming Cloud Lidar (WCL; Wang et al. 2009) was used to identify liquid-dominated and ice-dominated clouds.

\subsection{Parcel model simulation}

In this study, we compare the PSDs modeled using a parcel model containing SBM to those observed on the aircraft. The SBM was developed by Hebrew University (Khain et al. 2000) and has been implemented in the Weather Forecast and Research model (WRF; Lynn et al. 2005). Time-dependent drop freezing is not included in this scheme. The purpose of this simulation is not to evaluate the modeled results using observations, but instead to reveal the deficiency of 
131 instantaneous drop freezing in SBM and its inability to capture the observed rapid ice generation.

132 The modeled parcel has a depth of $500 \mathrm{~m}$. The observed drop size distribution at $-6{ }^{\circ} \mathrm{C}$ is used as

133 an input. The vertical air velocity is $10 \mathrm{~m} / \mathrm{s}$, which is a typical mean updraft strength in the

134 convective clouds sampled during ICE-T. The hydrometeor types include cloud drop/rain,

135 ice/snow, and graupel; the PSD of each hydrometeor type has 33 mass bins. The ice nucleation

136 mechanisms include immersion freezing using Bigg's parameterization (1953),

137 deposition/condensation nucleation (Meyer et al., 1992), contact nucleation (Meyer et al., 1992),

138 and the Hallett-Mossop process (Hallett and Mossop, 1974). Other ice microphysics processes

139 include riming, coalescence and diffusional growth. During every time step, $1 \%$ of the aerosols

140 in the ambient air are assumed to become entrained into the cloud parcel. The ambient aerosol

141 size distribution is observed using a high-flow dual-channel differential mobility analyzer

142 (HDDMA; DeMott et al., 2016) and a Passive Cavity Aerosol Spectrometer Probe (PCASP;

143 Baumgardner et al., 2011) operated on the C-130.

144 3. Results and Discussion

\subsection{Comparison of observed and modeled particle size distributions}

Fig. 1 shows the size distributions measured by the Learjet and those modeled using a parcel model with SBM. The simulation data on the left panels include all of the ice physics implemented in the SBM, while liquid-ice collision is turned off for the right panels. The Learjet measurements suggest that the ice particles observed in fresh developing convective clouds are relatively small (20-300 $\mu \mathrm{m}$ in diameter) between $-7^{\circ} \mathrm{C}$ and $-10{ }^{\circ} \mathrm{C}$ and that the PSD of ice broadens as the temperature decreases. The modeled ice PSD is much broader than that observed between $-7^{\circ} \mathrm{C}$ and $-10^{\circ} \mathrm{C}$. The deposition/condensation nucleation exhibits the largest 
contribution to the modeled ice PSDs (Fig. 1d). Immersion freezing, contact freezing and the

154 Hallett-Mossop process contribute less to the modeled ice PSDs. Small ice particles are mostly

155 formed by deposition/condensation nucleation, whereas large ice is produced by immersion

156 freezing and drop-ice collision (Fig. 1d and h).

157 An obvious difference between the observed and modeled ice PSDs is that large ice is not observed between $-7{ }^{\circ} \mathrm{C}$ and $-10{ }^{\circ} \mathrm{C}$ but is found in the modeled results (Fig. 1d). There are three possible explanations for this: first, large freezing (or frozen) drops cannot be identified from the images taken by the probes, or the sampling volume of the probes is too small; second, the modeled results are not realistic; third, there could be a combination of the first and second possibilities. Previous studies have suggested that during immersion freezing, large drops have a higher probability of freezing than small drops at the same temperature (Bigg, 1953). In addition, small ice that is generated by other mechanisms (e.g., deposition/condensation nucleation, secondary ice) can be quickly collected by large drops in convective clouds, which results in the freezing of large drops. There is no evidence that large drops do not freeze between $-7^{\circ} \mathrm{C}$ and $10{ }^{\circ} \mathrm{C}$. In the observations, only non-spherical particles are regarded as ice, but freezing drops exhibit no (obvious) shape deformation during the early stage of freezing (Johnson and Hallett, 1968; Hindmarsh et al., 2003). Due to the limitations of the instruments, freezing drops that do not exhibit obvious shape deformation cannot be identified; thus, the first possibility may apply. could result in a broad ice PSD at warm temperatures; because this is not true in natural clouds, the second possibility may also apply. Therefore, the large difference between the measured and simulated ice PSDs is probably both observation- and model-related.

175 Examples of particle images collected by the $2 \mathrm{D}-\mathrm{C}$ on the $\mathrm{C}-130$ and the CPI on the Learjet are 
shown in Fig. 2. Both the 2D-C and CPI images were measured near the cloud top in the updraft

177 cores of developing convective clouds. As noted in the figure, the observed ice particles mostly

178 comprise small frozen drops between $-8^{\circ} \mathrm{C}$ and $-10^{\circ} \mathrm{C}$ (Fig. 2c). Some particles may have just

179 begun freezing because they exhibit slight shape deformation, as shown by the particle images in

180 the red box in Fig. 2c; however, we have no other evidence with which to confirm this. Between

$181-10{ }^{\circ} \mathrm{C}$ and $-13{ }^{\circ} \mathrm{C}$, we observe more ice particles, including both large and small frozen drops, as

182 well as rimed graupels (Fig. 2a and b). Columns and plates were also observed. Considering the

183 time that is needed for columns and plates to grow, they were probably generated at a warmer

184 temperature than is observed. Due to the relatively low resolution of the 2D-S, 2D-C, HVPS and

2D-P images, large freezing (or frozen) drops that exhibit no obvious shape deformation cannot

186 be identified, and they are thus regarded as drops. In some spherical CPI particle images, it is

187 also difficult to determine whether the particles have begun freezing or not, because freezing

188 drops exhibit no (or no obvious) shape deformation during the early stages of freezing (e.g.,

189 Johnson and Hallett, 1968; Hindmarsh et al., 2003).

\subsection{Freezing time of supercooled drops}

To better understand the observed PSDs, we analyze the freezing time of supercooled drops in this section. Fig. 3 shows the changes in drop temperature and ice mass fraction with changes in time and ambient temperature. The updraft velocity is assumed to be $10 \mathrm{~m} / \mathrm{s}$. Drops and air parcels ascend from $-6{ }^{\circ} \mathrm{C}(\sim 520 \mathrm{mb}, \sim 5600 \mathrm{~m})$. The nucleation temperature, which is the temperature at which drops begin to freeze, is assumed to be $-8^{\circ} \mathrm{C}$. The figure demonstrates that a drop with a radius of $100 \mu \mathrm{m}$ cools from $-6^{\circ} \mathrm{C}$ to $-8{ }^{\circ} \mathrm{C}$ and begins to freeze at approximately $23 \mathrm{~s}$. The latent heat released due to freezing leads to a sudden drop in temperature from $-8^{\circ} \mathrm{C}$ to $0{ }^{\circ} \mathrm{C}$ (Fig. 3a), and the ice mass fraction increases from 0 to 0.1 (Fig. 3b). It takes approximately 
4 seconds for the drop to fully freeze; during freezing, the drop temperature remains at $0{ }^{\circ} \mathrm{C}$ (Fig.

$2003 a$ ), and the ice mass fraction continuously increases (Fig. 3b). After completely freezing, the

201 frozen drop rapidly cools due to the large difference between the ambient temperature and the

202 drop surface temperature. The cooling rate slows down when the frozen drop temperature

203 approaches the ambient temperature. According to its equations, the cooling rate for a drop in the

204 updraft is largely controlled by convective heat transfer, rather than radiation or diffusional

205 growth. If significant riming occurs on the freezing (frozen) drop surface, the cooling rate could

206 be slower, and the freezing time could thus be longer due to the latent heat release that occurs

207 during riming (Phillips et al., 2015). The drop temperature changes in a similar way for larger

208 drops as it does for small drops. However, due to their higher terminal velocity, it takes longer

209 for larger drops to reach their nucleation temperature $\left(-8^{\circ} \mathrm{C}\right)$. Drops with radii of $250 \mu \mathrm{m}$ and

$210500 \mu \mathrm{m}$ begin to freeze at $28 \mathrm{~s}$ and $43 \mathrm{~s}$, respectively (Fig. 3a), and their ambient temperatures

211 are approximately $-8.1{ }^{\circ} \mathrm{C}$ and $-8.15^{\circ} \mathrm{C}$ (Fig. 3c), respectively. In addition, it takes longer for

212 larger drops to completely freeze. Drops with radii of $250 \mu \mathrm{m}$ and $500 \mu \mathrm{m}$ require approximately

$21315 \mathrm{~s}$ and $35 \mathrm{~s}$, respectively, to fully freeze (Fig. 3a); these frozen drops are found at temperatures

214 of $-9.2^{\circ} \mathrm{C}$ and $-9.95{ }^{\circ} \mathrm{C}$, respectively (Fig. 3c).

215 Fig. 4 shows the freezing time and frozen temperature as functions of the drop radius for

216 different vertical air velocities and nucleation temperatures. The freezing time represents the

217 time period from the start of drop freezing to the end of drop freezing. The figure shows that the

218 freezing time increases as the radius increases. For the same nucleation temperature, drops freeze

219 faster in stronger updrafts than they do in weaker ones (Fig. 4a); however, their frozen

220 temperatures are colder in stronger updrafts (Fig. 4b). In addition, for the same updraft strength,

221 a drop freezes faster when its nucleation temperature is lower, and it fully freezes at colder 
temperatures. Moreover, for the same drop radius, the effect of the updraft strength on the

223 freezing time is smaller if a drop nucleates at a lower temperature, as is indicated by the smaller

224 differences between the solid, dashed and dotted lines for colder nucleation temperatures (Fig.

225 4a); however, its impact on frozen temperature does not vary substantially with different

226 nucleation temperatures (Fig. 4b).

227 Large drops may begin to freeze at warmer temperatures than small drops (Bigg, 1953). Fig. 5

228 shows the nucleation temperature and frozen temperature as functions of the drop radius. The

229 nucleation temperature is the temperature at which drops have a $10^{-4} \%$ probability of freezing, as

230 determined based on Bigg's parametrization for immersion freezing. This probability is low

231 because of the low concentration of immersion ice nuclei that are present at warm temperatures.

232 The figure shows that large drops may begin to freeze at warmer temperatures than small drops;

233 however, due to their longer freezing times, large drops may fully freeze at colder temperatures

234 than small drops if the updraft is strong enough. Immersion freezing is not the only ice

235 nucleation mechanism. In convective clouds, small ice can be generated at warmer temperatures

236 by other mechanisms (e.g., condensation/deposition nucleation). The ice PSD measured by the

237 Learjet indicates that large frozen drops were observed at colder temperatures than small ice, but

238 it is not known whether these large drops started to freeze before or after the small droplets, and

239 the mechanisms that lead to drop freezing are not well understood.

\section{$240 \quad 3.3 \quad$ Discussion}

241 The above analysis indicates that large frozen drops are observed at relatively colder

242 temperatures than small ice in strong updrafts of convective clouds but that they may begin to

243 freeze at warmer temperatures. If the vertical air velocity is not strong enough, large drops may 
descend or remain at the same level for long periods of time, and they may freeze if their temperature reaches the nucleation temperature. An example of this is shown in Fig. 6. In this case, penetration occurred approximately $500 \mathrm{~m}$ below the cloud top, as is indicated by the WCR reflectivity (Fig. 6a). The WCL power (Fig. 6c) quickly attenuated and the WCL depolarization ratio (Fig. 6d) is relatively low, which indicates that this cloud was dominated by liquid drops. At the flight level, the temperature (Fig. 6e) ranges from $-4{ }^{\circ} \mathrm{C}$ to $-4.5^{\circ} \mathrm{C}$ in the updraft and is approximately $-5^{\circ} \mathrm{C}$ near the cloud edge. The maximum updraft velocity is $7 \mathrm{~m} / \mathrm{s}$, and the mean updraft velocity is approximately $3 \mathrm{~m} / \mathrm{s}$. The Doppler velocity (Fig. 6b) is negative in most areas of the clouds, and its maximum value is approximately $4 \mathrm{~m} / \mathrm{s}$. The $2 \mathrm{D}-\mathrm{C}$ images clearly show the existence of ice (Fig. 6f). Most of the ice particles are frozen drops and graupel, and some are needles and columns. The graupel may fall from above; thus, they may start freezing at a colder temperature than the flight level temperature. Considering the time that is needed for the drops to freeze and for the needles and columns to grow through vapor diffusion, this ice may have nucleated when the cloud top was lower than observed.

The freezing of supercooled drops may be associated with some corresponding processes. For example, drops may break up or shatter during freezing, which can produce multiple ice fragments and splinters. Mason and Maybank (1960) showed that the freezing of a millimetersized drop may produce more than a hundred splinters. These ice splinters can enhance ice initiation in convective clouds. In addition, the change in drop temperature during freezing may exert impacts on the Hallett-Mossop process. Heymsfield and Mossop (1984) showed that the Hallett-Mossop process is not only related to the ambient temperature but is also related to the graupel surface temperature. In the SBM used in this study, the Hallett-Mossop process is only 
process may occur at colder ambient temperatures if the frozen drop (or graupel) surface temperature is appropriate (Heymsfield and Mossop, 1984). Fig. 3 shows that the drop temperature cools from $0{ }^{\circ} \mathrm{C}$ to its ambient temperature after being fully frozen and that the cooling rate may be even slower if there is significant riming on the surface of the particle (Phillips et al. 2015). During this process, if the drop surface temperature and other ambient conditions are suitable, the Hallett-Mossop process may occur at an air temperature that is colder than $-8^{\circ} \mathrm{C}$, which could also enhance the initiation of ice in developing convective clouds. For example, a millimeter-sized frozen drop can collect approximately 600 droplets in five seconds, assuming that the droplet concentration is $50 \mathrm{~cm}^{-3}$ and its diameter is $20 \mu \mathrm{m}$. Thus, two or three ice splinters may be produced if the ambient conditions are suitable. Moreover, time-dependent freezing can have an impact on the dynamics in developing clouds. The instantaneous freezing of a supercooled drop results in the sudden release of a large amount of latent heat, which may lead to an overestimation of the vertical velocity in modeled convective clouds. In contrast, timedependent drop freezing can affect the cloud dynamics in a different way because its latent heat is gradually released. Future studies are needed to explore these drop freezing-related processes.

This study reveals the importance of understanding drop freezing in convective clouds and allows us to interpret the observed ice PSDs; however, it also raises some specific questions about ice initiation. For example, it is not known why the observed "primary ice" concentration is much higher than the ice nuclei concentration (DeMott et al., 2016) and the modeled ice concentration (Fig. 1). There are several possibilities for this, including the production of ice 
questions requires a better understanding of the primary drop freezing mechanisms in convective

291 clouds, which in turn requires more laboratory experiments to be performed and more in situ

292 measurements to be obtained in the future.

\section{Summary}

In this study, the PSDs measured in fresh developing maritime convective clouds sampled during

ICE-T are shown and the deficiency of instantaneous drop freezing in models is discussed. The observations presented here suggest that the "first ice" that is observed is small. To interpret the observed ice PSDs, the freezing times and temperatures of supercooled drops are calculated. This analysis indicates that the freezing time is longer for large drops than it is for small drops. Due to the limitations of airborne instruments, freezing drops cannot be identified until they exhibit obvious shape deformation. If the updraft is strong enough, large freezing drops may be brought up to a colder temperature than their nucleation temperature before they begin to exhibit obvious shape deformation. This study allows us to interpret the observed ice PSDs in fresh developing convective clouds from the perspective of drop freezing. However, the mechanisms of drop freezing and ice initiation are still not well known. Future studies are required to evaluate model simulations using time-dependent drop freezing, to understand the impact of time-dependent mechanisms of drop freezing and ice initiation.

\section{Acknowledgments}

This work is supported by the National Science Foundation (Awards AGS-1230203 and AGS-

310 1034858), the National Basic Research Program of China under grant no. 2013CB955802 and

311 the DOE Grant DE-SC0006974 as part of the ASR program. The authors acknowledge the crew 
Atmos. Chem. Phys. Discuss., https://doi.org/10.5194/acp-2017-714

Manuscript under review for journal Atmos. Chem. Phys.

Discussion started: 15 September 2017

(c) Author(s) 2017. CC BY 4.0 License.

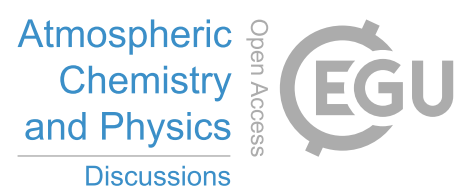

(c) (1)

312 of the NCAR C-130 and the SPEC Learjet for collecting these data and providing high-quality

313 products. Thank Drs. Paul Lawson and Sarah Woods for processing and sharing the data of

314 particle size distributions measured by Learjet.

315 


\section{References}

317 Alkezweeny, A. J.: Freezing of supercooled water droplets due to collision. Journal of Applied

318 Meteorology, 8, 994-995, 1969.

319 Baumgardner, D. and co-authors: Airborne instruments to measure atmospheric aerosol particles,

320 clouds and radiation: A cook's tour of mature and emerging technology. Atmospheric

321 Research, 102, 10-29, 2011.

322

323

Bigg, E. K.: The formation of atmospheric ice crystals by the freezing of droplets. Quarterly Journal of the Royal Meteorological Society, 79, 510-519, 1953.

Cantrell, W., and Heymsfield, A.: Production of ice in tropospheric clouds: A review. Bulletin of the American Meteorological Society, 86(6), 795-807, 2005.

DeMott, P. J. and co-authors: Sea spray aerosol as a unique source of ice nucleating particles. Proceedings of the National Academy of Sciences, 113, 5797-5803, 2016.

Dye, J. E., and Hobbs, P. V.: The influence of environmental parameters on the freezing and fragmentation of suspended water drops. Journal of the Atmospheric Sciences, 25, 82-96, 1968.

Field, P. R., and co-authors: Secondary Ice Production: Current State of the Science and Recommendations for the Future. Meteorological Monographs, 58, 7-1, 2017.

Foote, G. B., and Du Toit, P. S.: Terminal velocity of raindrops aloft. Journal of Applied Meteorology, 8, 249-253, 1969.

Hallett, J. and Mossop, S. C.: Production of secondary ice particles during the riming 
process. Nature, 249, 26-28, 1974.

336 Heymsfield, A. J., and Mossop, S. C.: Temperature dependence of secondary ice crystal

337 production during soft hail growth by riming. Quarterly Journal of the Royal Meteorological

338 Society, $110,765-770,1984$.

339 Heymsfield, A., and Willis, P.: Development of first ice hydrometeors and secondary ice in a

340 tropical oceanic deep convective cloud system near Africa. AIP Conference Proceedings, 1527,

$341972-975,2013$.

342 Heymsfield, A. J., and Willis, P.: Cloud conditions favoring secondary ice particle production in

343 tropical maritime convection. J. Atmos. Sci., 71, 4500-4526, 2014.

344 Hindmarsh, J. P., Russell, A. B., and Chen, X. D.: Experimental and numerical analysis of the 345 temperature transition of a suspended freezing water droplet. International Journal of Heat and

346 Mass Transfer, 46, 1199-1213, 2003.

347 Johnson, D. A., and Hallett, J.: Freezing and shattering of supercooled water drops. Quarterly

348 Journal of the Royal Meteorological Society, 94, 468-482, 1968.

349 Khain, A., Ovtchinnikov, M., Pinsky, M., Pokrovsky, A., and Krugliak, H.: Notes on the state-

350 of-the-art numerical modeling of cloud microphysics. Atmospheric Research, 55, 159-224, 2000.

351 Khain, A. P. and co-authors: Representation of microphysical processes in cloud-resolving

352 models: Spectral (bin) microphysics versus bulk parameterization. Reviews of Geophysics, 53,

$353 \quad 247-322,2015$.

354 Kumjian, M. R., Ganson, S. M., and Ryzhkov, A. V.: Freezing of raindrops in deep convective 
updrafts: A microphysical and polarimetric model. Journal of the Atmospheric Sciences, 69,

$356 \quad 3471-3490,2012$.

Lynn, B. H., Khain, A. P., Dudhia, J., Rosenfeld, D., Pokrovsky, A., and Seifert, A.: Spectral (bin) microphysics coupled with a mesoscale model (MM5). Part I: Model description and first results. Monthly Weather Review, 133, 44-58, 2005.

Mason, B. J. and Mayabnk, J.: The fragmentation and electrification of freezing water drops. Quarterly Journal of the Royal Meteorological Society, 86, 176-185, 1960.

Meyers, M. P., DeMott, P. J., and Cotton, W. R.: New primary ice-nucleation parameterizations in an explicit cloud model. Journal of Applied Meteorology, 31, 708-721, 1992.

Phillips, V. T., Khain, A., Benmoshe, N., Ilotoviz, E., and Ryzhkov, A.: Theory of timedependent freezing. Part II: Scheme for freezing raindrops and simulations by a cloud model with spectral bin microphysics. Journal of the Atmospheric Sciences, 72, 262-286, 2015. 623-634, 1973.

Pruppacher, H. R. and Klett, J. D.: Microphysics of clouds and precipitation. Atmospheric and Oceanographic Sciences Library, 954 pp, 2010. 
Atmos. Chem. Phys. Discuss., https://doi.org/10.5194/acp-2017-714

Manuscript under review for journal Atmos. Chem. Phys.

Discussion started: 15 September 2017

(C) Author(s) 2017. CC BY 4.0 License.

(c) (1)

375 of the Royal Meteorological Society, 131, 639-673, 2005.

376 Wang, Z., Wechsler, P., Kuestner, W., French, J., Rodi, A., Glover, B., Burkhart, M., and

377 Lukens, D.: Wyoming cloud lidar: Instrument description and applications. Opt. Express, 17,

$378 \quad 13576-13587,2009$.

379 Wang, Z. and co-authors: Single aircraft integration of remote sensing and in situ sampling for

380 the study of cloud microphysics and dynamics. Bull. Amer. Meteor. Soc., 93, 653-668, 2012.

381 Yang, J., Wang, Z., Heymsfield, A. J., and Luo, T.: Liquid-Ice Mass Partition in Tropical

382 Maritime Convective Clouds. J. Atmos. Sci., 73, 4959-4978, 2016.

383 Yao, S. C. and Schrock, V. E.: Heat and mass transfer from freely falling drops. Journal of Heat

384 Transfer, 98, 120-126, 1976.

385 
Atmos. Chem. Phys. Discuss., https://doi.org/10.5194/acp-2017-714

Manuscript under review for journal Atmos. Chem. Phys.

Discussion started: 15 September 2017

(c) Author(s) 2017. CC BY 4.0 License.
Atmospheric

Chemistry

and Physics

Discussions
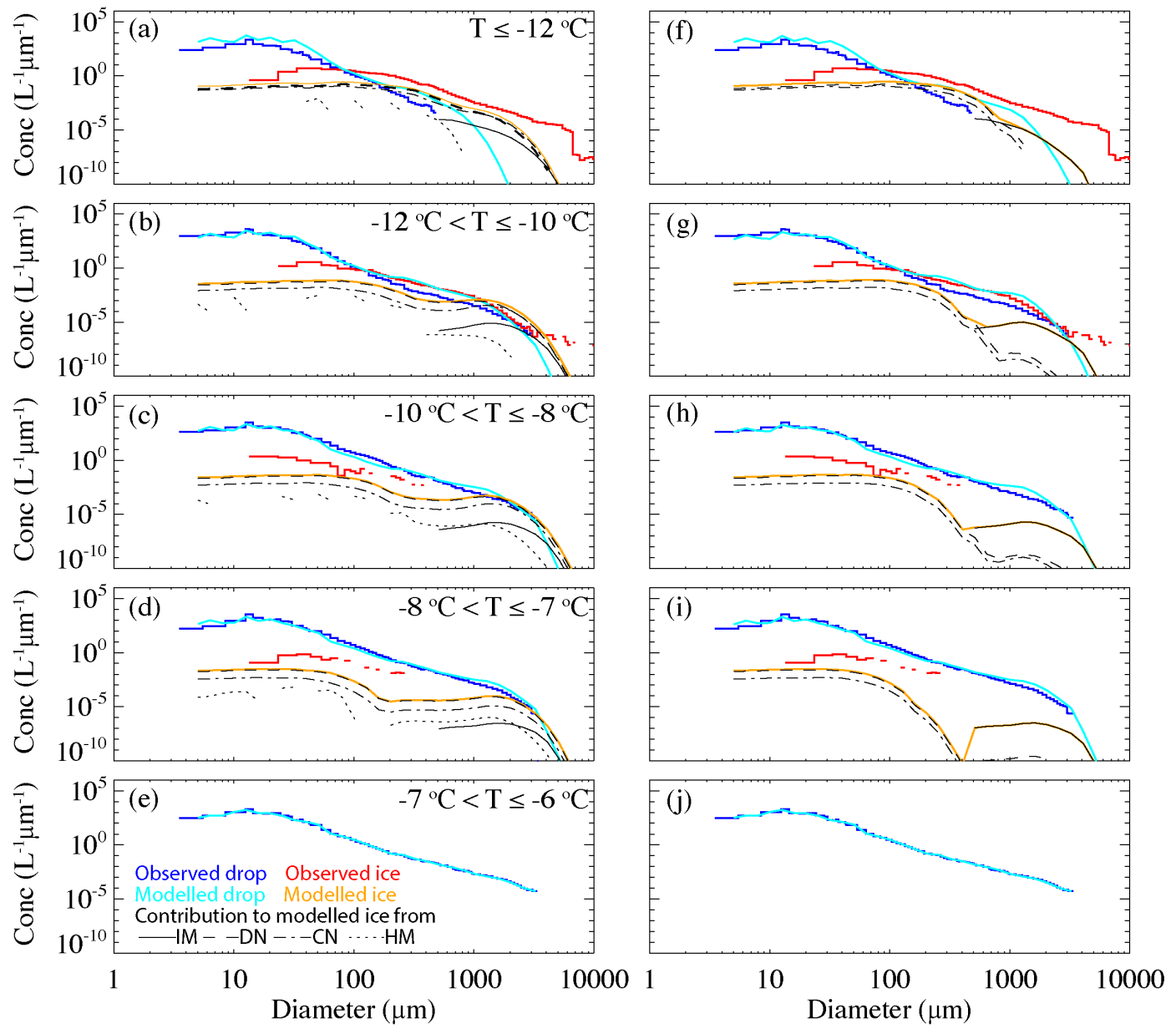

Figure 1. Particle size distributions in fresh developing convective clouds observed by the Learjet during ICE-T and those modeled using a parcel model with SBM. In the left panels, all of the ice physics implemented in the SBM are included; in the right panels, liquid-ice collision is excluded. The black solid, dashed, dashed-dotted, and dotted lines represent the contributions from immersion freezing (IM), deposition/condensation nucleation (DN), contact nucleation $(\mathrm{CN})$, and the Hallett-Mossop process (HM), respectively, to the modeled ice size distributions. 
Atmos. Chem. Phys. Discuss., https://doi.org/10.5194/acp-2017-714 Manuscript under review for journal Atmos. Chem. Phys.

Discussion started: 15 September 2017

(c) Author(s) 2017. CC BY 4.0 License.
Atmospheric

Chemistry and Physics

Discussions (b) $-10 \leq \mathrm{T}<-13^{\circ} \mathrm{C}$, CPI images
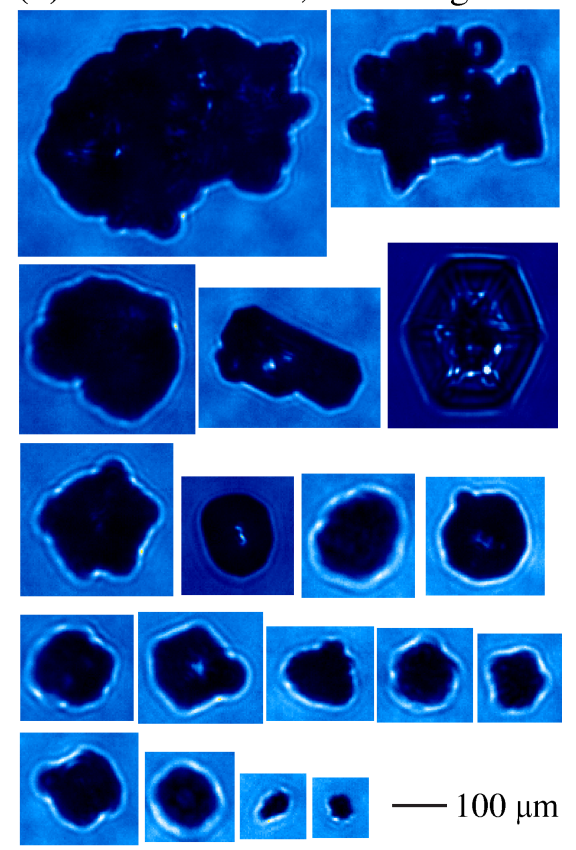
- $\odot \circ 00 \bigcirc-100 \mu \mathrm{m}$

Figure 2. Examples of the 2D-C and CPI images measured in the developing convective clouds sampled during the ICE-T project. 
Atmos. Chem. Phys. Discuss., https://doi.org/10.5194/acp-2017-714

Manuscript under review for journal Atmos. Chem. Phys.

Discussion started: 15 September 2017

(c) Author(s) 2017. CC BY 4.0 License.

(c) (1)
Atmospheric

Chemistry

and Physics

Discussions
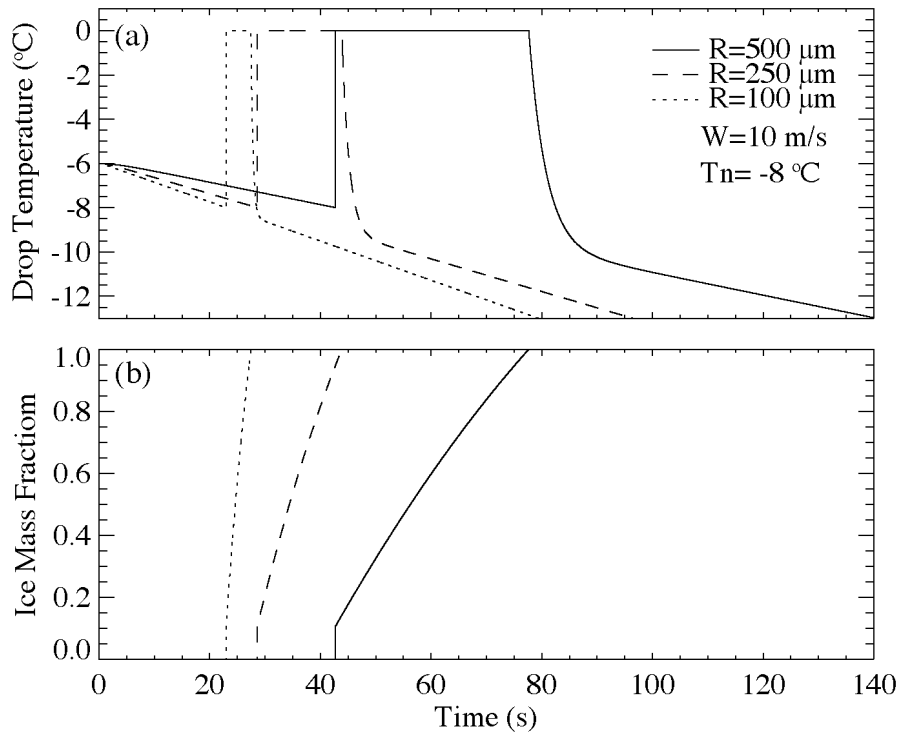

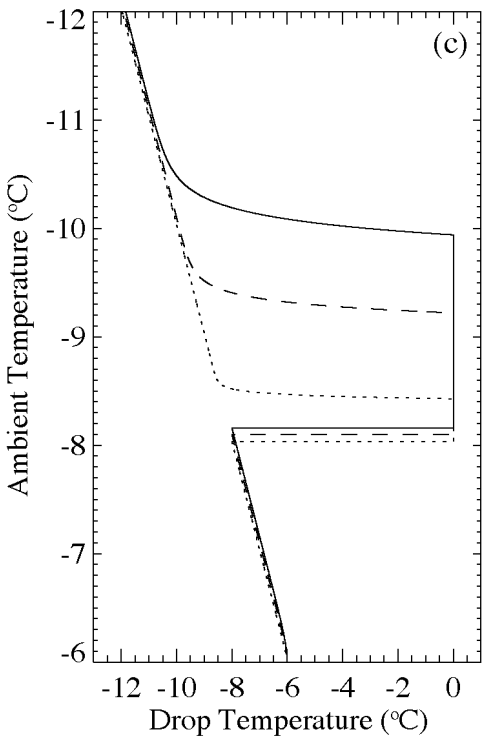

Figure 3. (a) Changes in drop temperature over time for drops with different radii. Vertical air velocity (W) is assumed to be $10 \mathrm{~m} / \mathrm{s}$ and nucleation temperature (Tn) is $-8 \mathrm{C}$; (b) same as (a) but for ice mass fraction; (c) ambient temperature versus drop temperature for drops with different radii. 
Atmos. Chem. Phys. Discuss., https://doi.org/10.5194/acp-2017-714

Manuscript under review for journal Atmos. Chem. Phys.

Discussion started: 15 September 2017

(c) Author(s) 2017. CC BY 4.0 License.
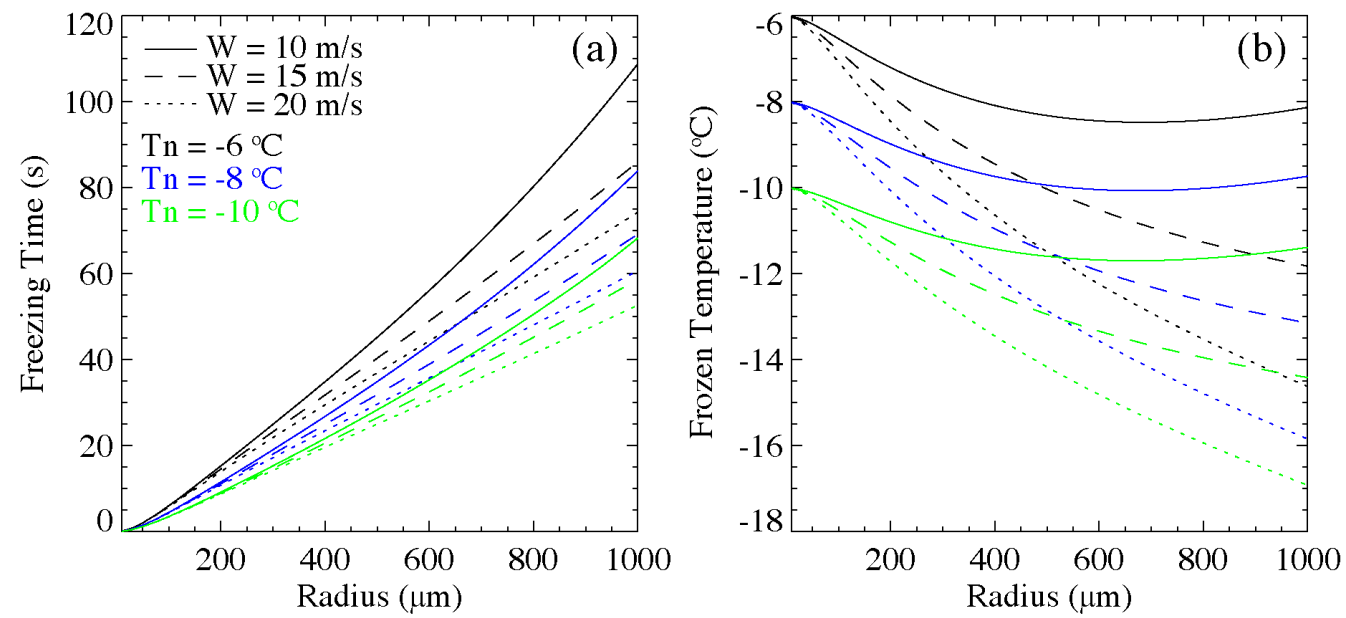

Figure 4. (a) Freezing time and (b) frozen temperature as functions of drop radius for different values of vertical air velocity $(\mathrm{W})$ and nucleation temperature $(\mathrm{Tn})$. 
Atmos. Chem. Phys. Discuss., https://doi.org/10.5194/acp-2017-714

Manuscript under review for journal Atmos. Chem. Phys.

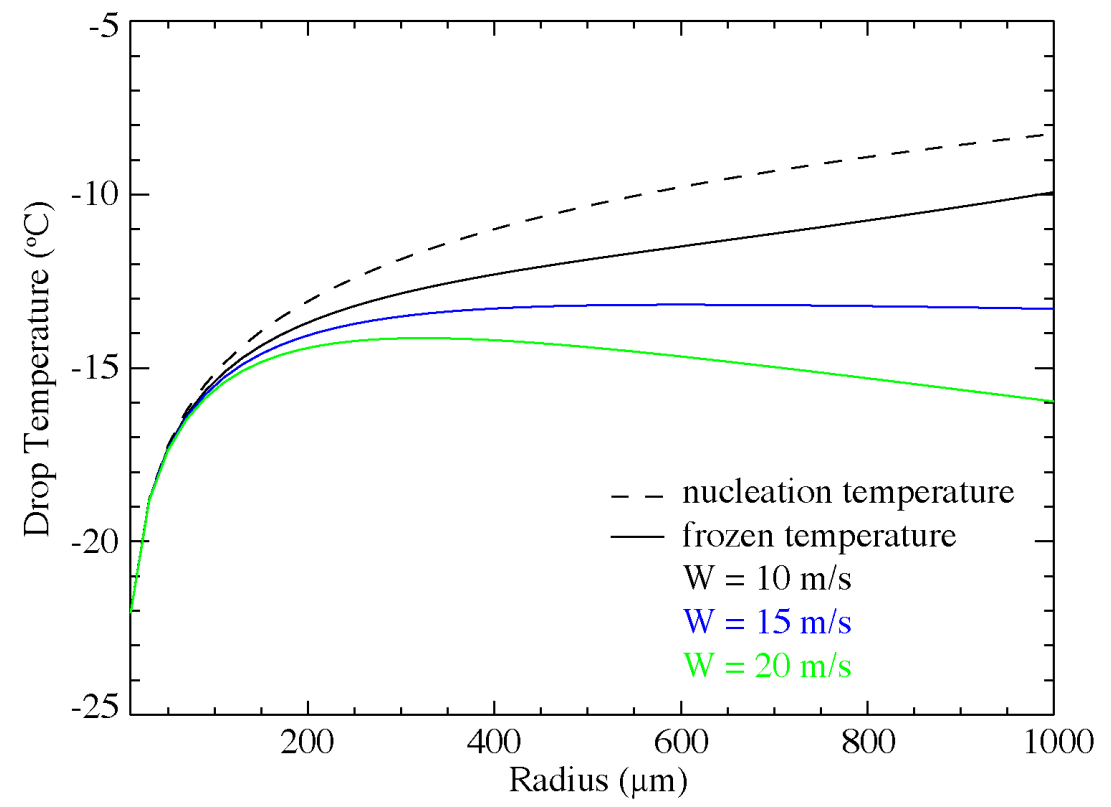

Figure 5. Drop temperature as a function of drop radius for different vertical air velocity (W) values. The nucleation temperature is the temperature at which drops have a $10^{-4} \%$ probability of freezing, as determined based on Bigg's parameterization for immersion freezing. 
Atmos. Chem. Phys. Discuss., https://doi.org/10.5194/acp-2017-714 Manuscript under review for journal Atmos. Chem. Phys.

Discussion started: 15 September 2017

(c) Author(s) 2017. CC BY 4.0 License.
Atmospheric

Chemistry

and Physics

Discussions
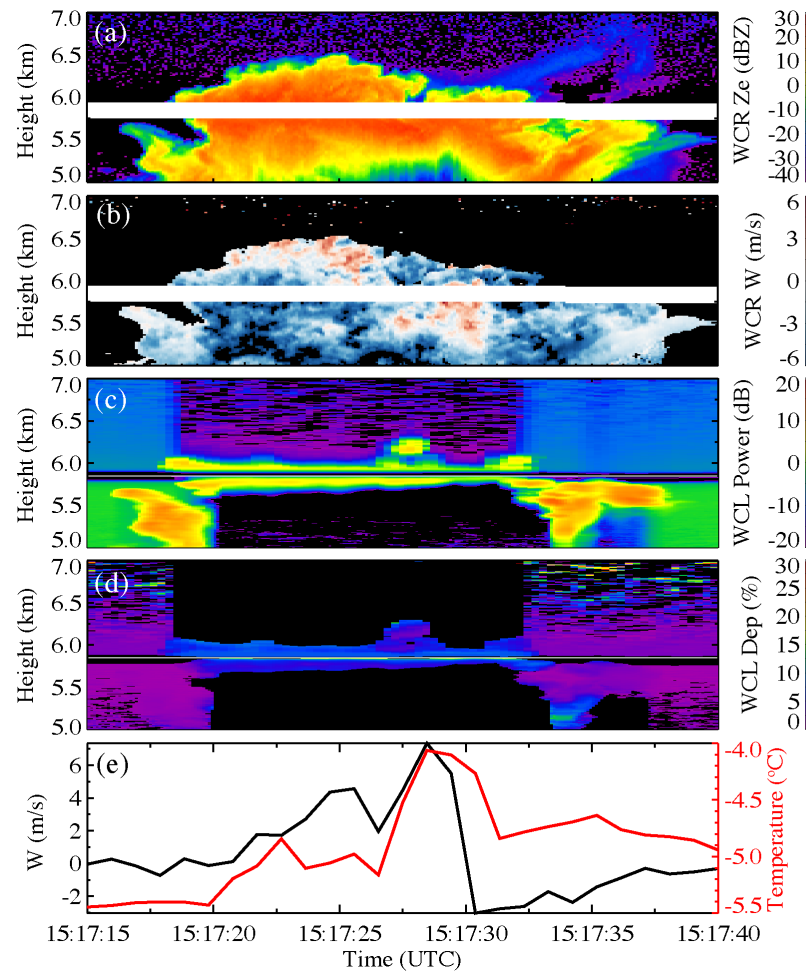

(f) Example of Ice:
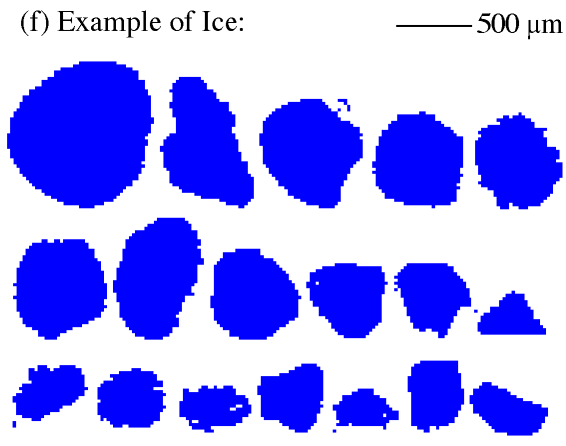

COPOPOE

botstopese

Q tobllogkent

$-0 \rightarrow+4.1$

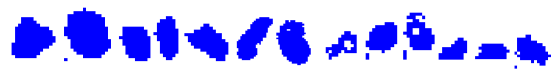

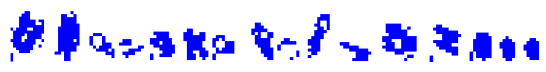

Figure 6. An example of the penetration of the C-130 in a developing cloud sampled on 23 July 2011: (a) WCR reflectivity; (b) WCR Doppler velocity; (c) WCL power; (d) WCL depolarization ratio; (e) ambient temperature and in situ vertical air velocity; and (f) examples of ice particles measured using 2D-C. 